\title{
Developing curriculum design for the 21st century - Balancing the need of character building and meeting other emerging needs of the future
}

\author{
$\mathrm{Ng}$ Soo Boon \\ Curriculum Development Division, Ministry of Education Malaysia
}

\begin{abstract}
How to cite
$\mathrm{Ng}$, S. B. (2020). Developing curriculum design for the 21 st century - Balancing the need of character building and meeting other emerging needs of the future. Asia Pacific Journal on Curriculum Studies, 3(2), 1-10.

https://doi.org/10.53420/apjcs.2020.4
\end{abstract}

\begin{abstract}
The advent of Industrial Revolution 4.0 with the seemingly unstoppable rapidly advancing and proliferation of emerging technologies such as Artificial Intelligence, Internet of things, 3D printing infiltrating our everyday living brought forward the need to keep abreast of latest inventions as it was repeatedly emphasized that future jobs hinges on knowledge and skills in these inventions and skills. However, surfacing at the same time is the changes in the social fabrics and social cohesion as well as family values and belief systems. Fast changes creates more social inequality and confusion in our traditional value system. Society is increasingly plague with dichotomy and conflicts, the line between just and injustice as well as rights and wrongs is blurring. As education is preparing the learners for the future, educators grapple with a future which is rather unknown and try to figure out the perceived needs of this century ranging from technological skills, cognitive skills, learning skills, literacy skills, life skills, social skills to intrapersonal skills. There is an urgent need to determine our priority, how should we package all these knowledge and skills into school curriculum? Should the curriculum design be more humanistic or retain the largely behaviouristic one embraced in the last century. Competence based curriculum proposed by UNESCO IBE seems to be a preferred curriculum design in many countries. Competence based curriculum which has been used widely in technical courses is widening its scope to include values and ethics. Could values and character building be stated sufficiently in the form of competence? It is my view that character building and values is best look upon from the practice and ethics perspective and this requires strategic and deep thinking. A thinking based curriculum cannot be void of these character building and values components, it should be enhanced by them. Core competences required to fulfil the Sustainable Development Goals in the UNESCO 2030 agenda has an undertone of values and ethics and should be the focus of the curriculum design of the 21 st century. Truly in this century the need to develop the future generation of learning to be, learning to live together, learning to know, and learning to do, the four pillars uphold by UNESCO is so much relevant and needed. There is a need to harmonize humanistic curriculum design with behaviouristic curriculum design as we embrace transformation in the way we do things and we live our everyday life brought about through Industrial Revolution 4.0. We need to look inward spiritually and to develop the inner being so that we can live in peace with ourselves, with others and make decisions for the common good of all. Any content oriented curriculum do not need to be void of character building if we adopt pedagogies requiring students to think through ethical dilemmas and propose best course of action in the face of conflicting choices (Chowning \& Fraser, 2007; Kelley, \& Knowles, 2016). At the same time, future curriculum need to break away from the present subject based design but to look beyond, moving into more multidisciplinary, trans-disciplinary where the lines between subjects are blurring, where big ideas are being explored and where learning can be more holistic and meaningful.
\end{abstract}

Keywords: curriculum design, character development, 21st century education

\section{Background: Perceived Needs of the 21st century}

Curriculum developers wear two lens, one is looking at current time as the students are living in the present, that is easier to handle; however, the other long distance lens is into the future. In that aspect, curriculum developers are like the magician looking into his magic ball, they must be able to predict the future since they are planning to prepare the learners for the future that has yet happened. At this moment of time in 2019 there are many keywords or niche words floating around such as Artificial Intelligence (AI), 4th Industrial Revolution (4IR), global citizenship, digital citizenship. These are keywords describing what the 21 st century needs. We are already almost two decades into 21 st century, are we getting it right? 
Looking around, our perceived needs seem to be lingering more around STEM skills and life skills. As we equip our students with all these emerging skills, we are also exposing students to other needs, changes in the technological front is creating social tension and social inequality. This fast changing world is creating the needs to prioritise and focus amidst the myriad of happenings and choices, to make rapid decision between two seemingly 'grey areas', to embrace diversity and yet retains self-identity, to develop self-resilience and yet collaborate. The emergence and re-emergence of concepts such as Happiness Curriculum, Social Emotional Learning (SEL) is a tell-tale that all is not so well at the educational front, among critics are that the product of our education system are not able to think, they are not innovative, they are not resilient, they are weak in spirit and not courageous. Other than that, there is also uncertainty at the curriculum front, what should the future curriculum looks like, or do we really need a national or state level curriculum at all?

The report on 'The Future of Jobs: Employment, skills and Workforce Strategy for the Fourth Industrial Revolution (World Economic Forum, 2016) reiterated that young people now need more than the traditional and academic skills to survive. Ten skills were listed by World Economic forum as most important for the year 2020, top the list is complex problem solving skills followed by critical thinking and creativity, people management, coordinating with others, emotional intelligence, judgement and decision making, service orientation, negotiation and cognitive flexibility (World Economic Forum, 2016). These ten skills suggested focuses on the soft skills, is it indicating that countries do not need to equip its citizens with the hard skills or vocational skills to get work done? It is unlikely to be so. How the 21 st century curriculum should looks like? What should be the formula? Are all these soft skills, cognitive, technological skills competing with each other in term of priority? The plate is really overflowing, with schooling hours remain the same, and how do curriculum developers strategise to align all these skills. There are many suggestions, such as that of Paige (2009) who suggested that a 21st century curriculum should blend knowledge, thinking, innovation skills, media, Information and Communication Technology (ICT) literacy, and real life experience in the context of core academic subjects. There are however thinking that the best way to impart these 21 st century skills is through interdisciplinary, transdisciplinary and neodisciplinary approach (Delaforce, 2016) where traditional subjects should not be 'standalone' anymore.

Outcome based curriculum design has always been used in developing school curriculum especially for STEM subjects. Humanistic curriculum design is not so rampantly used in school curriculum but more for programmes In recent years, competence based curriculum alleged to be able to align knowledge, skills and values emerged and playing a more central role now. This article explores this issue of developing a curriculum for character building from the perspective of a practicing curriculum developer, contemplates on how to harmonise on outcome based curriculum design and humanistic curriculum design through a whole school curriculum and thinking based curriculum. A suggestion of using Sosio-Emotional Learning theory as a basis for this endeavour is also discussed.

\section{The purpose of Education}

It is pertinent at this moment of time to first pause and reflect upon the purpose of education. In most cases, educators especially the curriculum developers always talked about 'developing the full potential of each individual so that they can live morally, creatively, and productively in the society'. This actually is a two prong approach, one is for the sake of the community and the state where these young learners will ultimately become responsible and contributing members to ensure continuous prosperity and wellbeing of the community and state, the other is about developing the individual himself for self-fulfilment, the basic rights of an individual. An individual thus has the responsibility to learn up some knowledge and skills so that they can contribute back to the society and so that he or she can find a living, the state in turn owe it to the democratic society to educate each of its members for self-actualisation. However often the state perhaps in its pursuit of development has disregard or place less emphasis on the self-actualization part. The goal of the state supersede that of the individual.

Compare this current thought with Plato who emphasized that the purpose of education is to produce citizens of good character and this can be achieved only through a holistic curriculum with a balance in physical education, arts, mathematics, science, character and moral judgment (Dewey, 1916). Dewey proposed that education is not preparation for life but education is life itself because all that society has accomplished for itself is then put through the agency of the school, and it is at the disposal of its future members (the learners in the schools) (Dewey ,1956). At the same time, all the society's better thoughts of itself it hopes to realize through the new possibilities is opened to its future self, the learners themselves (Dworkin, 1959; Dewey, 1956). Education is this training of the future self of the society. Dewey believes that the business of education is to stimulate this future self's powers by the demand of the social situations in which he finds himself in and to cultivate deep-seeded and effective habits of discriminating tested belief from more assertions, guesses and opinion (Dworkin, 1959). Thus learning is best achieved through involving students in an environment where they accumulate experiences of exploration, socialization and communication. One can see that Dewey is adopting a more holistic approach to education. He is focusing on developing the child himself. Dewey's 
idea of education provide the missing link to what some critics of education coined as the de-humanisation of education. Perhaps in trying to provide for the physical development of the state and to provide for comfort of the people to sustain life, we miss the humanizing part.

Sokka Gaggai has emerged globally after the Second World War with an increasing number of followers, it is aligned to Buddhism. Sokka Gaggai reiterates that the true goal of education should be the cultivation of the individual character on the basis of respect for humanity (Ikeda, 2010). In Islam, the main purpose of acquiring knowledge is 'to bring man closer to God, to gain good of this world and not to destroy it through wastage and arrogance and in reckless pursuit of higher standards of material comfort, to spread freedom and dignity, truth and dignity, truth and justice, it is not to gain power and dominance for its own sake' (Al-Attas, 1997). The Christian Bible speaks about the moral and spiritual instruction to the believers, it places a high value upon knowledge, both of God and of His works, and it describes the moral and spiritual fruits of this knowledge and defines its ultimate purpose. Religion teaches us to seek truth and goodness, to believe and trust God, it teaches us about good and bad. It is about bringing us up to be a good person, building up our character. Although challenge remains, perhaps secular education do need to co-exist with religious education as the common aim is to develop the character of the people.

\section{Curriculum Design for the 21st Century}

Curriculum design delineates the organization of the content, pedagogical approach as well as assessment principles regarding the program of learning. Outcome based curriculum design which is very behavioural in its nature was the preferred design for more than 70 decades since Tyler advocated it as a suitable method for a national curriculum. It is a very pragmatic design and is still relevant today in many countries. However together with it, the humanistic design has also been used in some places and in this 21 st century there is a need to explore further on it.

\section{Outcome based curriculum design}

Outcome based Education (OBE) is largely a norm in STEM education and training; engineering and technical subjects are among the first to adopt OBE curriculum design, 4IR is basically STEM driven. OBE become a necessity as democratisation of education provides affordable education to almost everyone in the society. As society becomes more affluent, adults and parents begin to hold schools and teachers accountable for students' learning. Education fraternity by itself expanded rapidly and in order to ensure uniformity and control, the traditional model of focusing on resources and content (inputs) that is made available to each student has been transformed to establishing outcome, measurable and observable that students can demonstrate to indicate that they "know and are able to do" whatever the required outcomes are. Outcome-based curriculum design is based on the behavioural theory of learning and mastery learning where the assumption is that if each part of the educational system develop goals (outcomes), by the end of the entire educational experience, each student would have achieved the final goal of education.

In developing OBE curriculum, observable and measurable learning objectives or learning outcomes are carefully formulated first before the learning activities or experiences are design, assessments is then designed based on these aspired outcomes. How will we know is one of the key question in OBE. In some instances, a backward curriculum design is used where assessment is determined before relevant learning activities and appropriate content are selected. This is done to ensure that the learners are able to demonstrate achievement of outcomes, and that learning outcomes, learning acitivities/methods and assessment are aligned. Students' performance become the priority. While outcomes represent the destination of the learner's journey, the pedagogy, activities, tools and methods of reaching the destination are flexible. In another word, there is flexibility to cater for the unique needs of their learners. This is a common design used worldwide. This trend will probably continue as on the surface it provides a method to ensure students acquired the competences needed in tackling the onslaught of 4IR.

The problem with OBE curriculum is that in some countries, learning outcomes predominantly focuses on mathematics, language, science, and history, without referring much to attitudes, social skills, or moral values as social skills and values are difficult to measure within the span of schooling. This has contributed to the onslaught of 'dehumanising education' as claimed by some sectors of education.

\section{Humanistic curriculum design}

The ultimate purpose of education through the eyes of advocates of humanistic approach is that education is for the benefit of humanizing mankind. Humanising mankind emphasizes on human rights, the right to express opinions, the right to learn, to think and to act in accordance with the noble values and humanitarian norms (Fauzan Akmal, 2017). Humanising mankind liberates them from the 'oppressive system' and raised awareness of the critical processes centered on educators and learners as subjects in 
the process of teaching and learning (Freire, 1970). Freire proposed a more world-mediated, mutual approach to education that encourages the co-creation of knowledge. The subject in education is then the teachers and students and not the content matter, this is contrary to many existing programs where the objective of learning is the subject matter and not how the child has developed in his personality and character through the learning. This is consistent with some criticism that current education loses the humane aspects (dehumanization) because teaching is teacher-centered and not student-centered (Fauzan Akmal, 2017), or what matter become what teacher teach and not what students learnt.

Looking at the granular scale, the humanistic curriculum design emphasise on the child itself, the purpose of education is for selfrealization and self-actualization of the individual child, education has the responsibility to develop this child's potential fully, of utmost importance is his self-concept, it is believe that if the student feels good and positive about himself or herself that is a good start (Fauzan Akmal, 2017). This child develop positive self-concept when he or she is encouraged to think critically and act according to the values of humanity. His self-reliance, self-esteem, and self-sense of ethics upholds his values system and develop him to be the agent of humanizing the society, with good personality and character. Education is the basis of the formation of this human personality (Fauzan Akmal, 2017). In this perspective the acquisition of specific knowledge and skills become the peripheral and not the core of learning.

Educate the child and not teach the subject, this is the crux of humanizing education, this is consistent with Dewey's idea of education is life and not just preparation of life. The challenge is how we go about it. Can a national curriculum focusses on humanistic approach and assume that specific subject matters will be caught along the way? The advocates of OBE curriculum design might not think that this is possible. Subject matters have become so specialized that the future employers think it is important to be imparted, they form the content of the lesson. James Harvery from the Center on Reinventing Public Education US argued that school education is more than for job training, schools has for centuries prepare students for life and work. Life is made up of not only college or work, but also for living within a family, a community, as global citizen. The responsibility of schools is more than for future employment. This is consistent to what Dewey's idea of education is life (Harvey, 2000).

In the 20th century, we lament that many do not have access to education. When education has reached all, Education for All has become a reality we begin to question why is it that the children of today are less grateful, less respectful of the elders, to their parents, why are they not giving up their seats to the weak and elderly. We also begin to see product of our education system whom we have taught them diligently the skills of doing their business and sciences, how they can earn money and oblivious of their manufacturing process which is polluting the world, how people can earn money out of illegal human trafficking etc. Something is wrong somewhere and this is the issue to be tackle as we enter into the third decade of the 21 st century. As 4IR reduces the distance between each corner of the world, as human become closer in distance, what each one does will ultimately affect many others; news of evil doing reaches us faster, evil produces more evil, as more people get to know the evils, thus the ethics of doing thing become very important. The ethics of doing things is influence by the character of each individual.

Character is not a set of moral traits or values, it is the manifestation of the values and principle we held, it reflects who we are. Character building is a lifelong work. Good traits or moral values are learned in the process of making choices and decisions forming each of our character (geniusinchildren.org, 2019). As adults and educators, we watch for opportunities or design activities to see the children through the challenging experiences they encounter. The child himself or herself has to understand and learn from the consequence of their decision and choice, this form a core bank of experiences they can reflect on when making future decisions as they grow. In the process, they learn to become themselves, equipped with skills such as thoughtfulness, courage and humanity, this sets out to mould their character, something that they have to do it on their own, as educators, we can only help to shape their character. This brought forth the need to expand the idea of curriculum to include all experiences the child encounter when they are in school. School culture and school ambience play a big part in developing the character of the students. Developing character does not only happen in classroom, it happen in all happenings in the school.

\section{Harmonising humanistic curriculum design and outcome based curriculum design}

Ideally, developing younger generation with good character, balanced in his or her approach and is able to uphold and contribute to the development of the community and country should be the ultimate aim of education in countries around the world. In this 21 st century, the advent of new technologies and new scientific discoveries have changed the kind of occupations and the way work are being done. In an increasingly highly technological environment, behaviouristic or outcome-based curriculum design where clear and precise learning outcomes are specified facilitate the learning organisations such as schools and colleges in preparing students especially for future job and keeping track of the kind of knowledge and skills students need to acquired. However, even back in 1981 itself Alvin Toffler in his book 'Learning for Tomorrow' predicted that future curriculum could no longer be designed concentrate on the learning of precisely defined skills and acquisition of subject matter (Toffler, 1974). OECD 
study (OECD, 2018) has identified skills necessary for 21st century and half of it are not easily observable and measureable competencies, these are the competencies which is hard to measure through the conventional subject matter approach. There must be a synergy between outcome based curriculum design and humanistic curriculum design. There must be a rethinking of how learning takes place in our education fraternity. This synergy can be realized through whole school curriculum and thoughtful curriculum.

\section{Whole school curriculum}

The sum of the whole is not equal to the parts. Harmonizing humanistic curriculum design and outcome based curriculum design does not mean literally letting both designs to exist side by side. There must be a 'gelling component', a well thought of synergy seamlessly integrate both. In this case, school curriculum need to be expanded to include all learning that is potentially available to all students, it is the learning experiences students acquired during their schooling (Bobbit, Caswell \& Cambell in Saylor \& Alexander, 1974). Literature in curriculum talk about prescribed curriculum, hidden curriculum, latent curriculum, tacit curriculum as curriculum experts realize that learning happen also outside the classroom and not only through subject matter. Hidden curriculum, tacit and latent curriculum include school ambience, rules and regulations set by school, role of students in management of schools. In many instances, the moment that we remembered most of our schooling does not happen in the lesson taught in the classroom. Whole school approach mean that there must be in existence a school curriculum which need to be designed in a holistic manner, taking into consideration local context, needs of its students and not confined to traditional subjects. This is consistent with Longstree and Shane's (1983) idea of dynamic curriculum. Subject matters are only one of the mean where learning takes place and learning is not only the subject matters but it is the total learning experience students obtained right from the minute he or she enter the school. The school climate need to be planned to reflect the ethos of the school, the philosophy of learning and the direction of the school. School climate is about the norms, goals, values, interpersonal relationships, teaching and learning practices, organisational structures of a school (Macneil, Prater, \& Busch, 2009). It is only through this perspective that education can achieve its purpose of developing the ethical student with good character.

An example of this whole school curriculum is the concept of Tokkatsu (tokubetsu katsudo) Model of Holistic Education in Japanese school. Japanese students are given the responsibility to plan and organise group activities throughout the day within or out of the classroom learning, they collaborate and make joint decision making on projects and tasks they are involved in. Examples of activities can be as 'trivial' as keeping classroom clean, projects, organizing sports day, school excursions, student councils, club activities (Educating the whole child TOKKATSU www.p.u-tokyo.ac.jp assessed on 1 July 2019) Students are given responsibility to lead and plan these activities on their own. Through these activities, students develop positive relationships with others as well of individuality, its aim is the well-balanced development of the mind and body of students much of what is encouraged through socio-emotional learning (SEL).

\section{Thinking-based curriculum design}

Thinking does not happen in a vacuum. A thinking-based curriculum should focuses on creating 'thinking schools' where every level of the school is involved in inquiring, decision making and problem solving, continuously and not sporadically. schooling of the mind happens, the product of which is thoughtfulness (Udall \& Daniels, 1991, Wiggins, 1987; Perkins, 1992; Costa, 1991). Systematically, teachers in these schools need to plan and integrate thoughtfulness in teaching and learning inside and outside of the classroom. A habit or disposition of thinking is thus inculcated within the members of the school, not just thinking skills in a fragmented manner. Thoughtfulness in this respect is two prong: cognitive and affective. From the cognitive aspect, thoughtful bring forth the idea of mindful and full of thoughts, from the affective aspect, it deals with the attitude of caring, considerate, integrity, honesty $(\mathrm{Ng}, 2004)$. A thinking-based curriculum enable students to be involved in projects either in a more academic setting or serving the communities in and out of school or globally. Sustainable Development Goals in the UNESCO 2030 agenda provide a very suitable context and a ready platform and rich context for students to delve into real life issues, many of which has elements of ethics involved and would involve deep thinking. The existence of this thoughtful learning curriculum and environment (Costa, 1991; Costa \& Kallick, 2000) enable the development of character among the students. Developing good character and making ethical decision is a thinking process. A wise person is a thinking person, people with high moral values have think through the issues and make his or her stand, thus a truly thinking schools must have adopted social and emotional learning in its thinking.

\section{Developing Character through Social and Emotional Learning (SEL)}

Building character is both doing the right thing and being true to yourself (geniusincildren@org, 2019). The prerequisite in understanding oneself which subsequently lead to self-actualization is to know and manage ones' emotion, accepting and 
respecting the uniqueness of oneself. Social and Emotional Learning(SEL) is this process where we learn to recognize and manage our emotions, feel and show empathy for others, behave ethically and responsibly, develop positive relationships and make good and responsible decisions. The roots of SEL can be traced back to Plato through his book 'The Rebuplic' where he proposed a holistic curriculum with a balance in physical education, arts, maths, science, character and moral judgment. He reiterated the purpose of education is to produce citizens of good character. SEL became dominant in 1980s in New Haven US and subsequently in 1994, the Collaborative to Advance Social and Emotional Learning (CASEL) was set up. When Daniel Goleman published his book "Emotional Intelligence: Why it can matter more than IQ' in 1995, it enhances the theoretical basis for SEL and SEL begin to grow at a faster pace.

Through the years, CASEL has identified and developed competences for SEL. SEL competences made up of self-awareness(with a growth mind-set), self-management, relationship skills, and responsible decision making, three more competences were added in 2018 though the Devereux Student Strengths Assessment (DESSA, 2018), which are goal oriented character, personal responsibility and optimistic thinking. Recognizes the role of SEL especially in this digital age, OECD proposes the Big Five Domain which are task performance(conscientiousness), emotion regulation(emotional stability), collaboration (agreeableness), open-mindedness(openness to experience), engagement with others(extraversion) as in Figure 1. These domains and the 19 skills identified with it are not something that can be taught theoretically in the classroom but can only be caught through experiences that students go through, where character building process happens. OECD believes that these domains drive critical life outcomes and if it is prioritized in schools it can educate hearts, inspire minds, and help students navigate the world more effectively (OECD, 2018). The identification and formulation of these SEL competences can facilitate the fusion of humanistic curriculum design and outcome based curriculum design in developing school curriculum with SEL as its theoretical basis. SEL competences can co-exist or fused with other learning competences. However, a more authentic and valid assessment methodology need to be further explored.

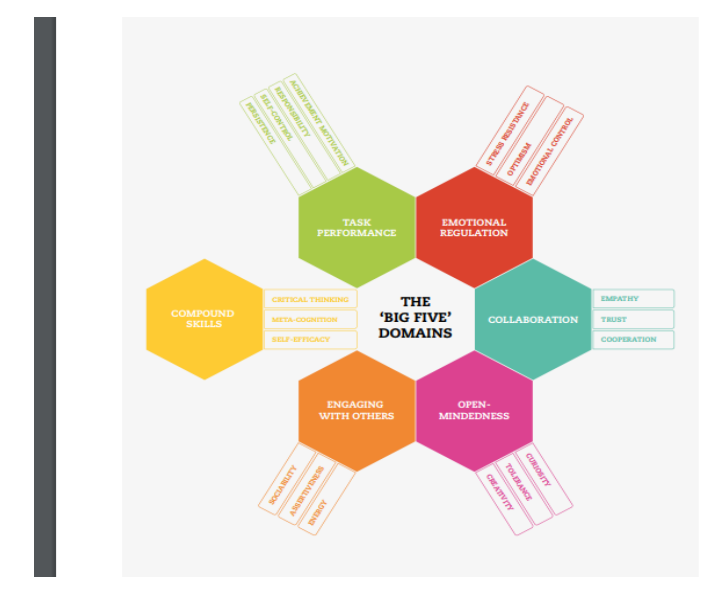

Figure 1. The Big Five Domains in SEL by OECD (2018).

Though SEL competences can be imparted through academic curriculum, as a free-standing lesson or infusing it into teaching practices, for its success, it needs a system of support. This system formulate policies and organizational structures to support students' social and emotional development, and to create a supportive teaching and learning environment for the teachers. In fact, it has been identified that the quality of teacher-student interactions is most important in SEL (Hamre \& Pianta, 2007; Mashburn \& Pianta, 2006 in CASEL, 2015). Equally important are the interpersonal relationships between peers, clarity and consistency of school rules and physical safety of school, leadership practices. SEL will eventually enhance students' capacity to learn and to integrate skills, attitudes, and behaviours to deal effectively and ethically with daily tasks and challenges behavioural problem will be reduced (National School Climate Council, 2007 in CASEL, 2015). An integrated pedagogical approach will be useful as it promotes intrapersonal, interpersonal, and cognitive competence which in turn enable the possibility.

\section{A Meeting of Mind and Skills through Integrated Pedagogical Approach}

Integrated education is a fusion of the various disciplines of knowledge where the focus of learning is not the individual discipline in itself, but on solving problems or producing something. In this age of knowledge exploration, new information is being churned out at a rapid rate, there is no way for school system to literary catch up with the latest knowledge constantly, students need to be tasked and equipped with the competence to seek for information and use them. The era of Industrial Revolution 4.0 also brought 
about constant changes in competences (knowledge or skills), this is driving the need for the education sector to consider multifaceted, transdisciplinary and integrated competences (Marope, 2017) as shown in Figure 2.

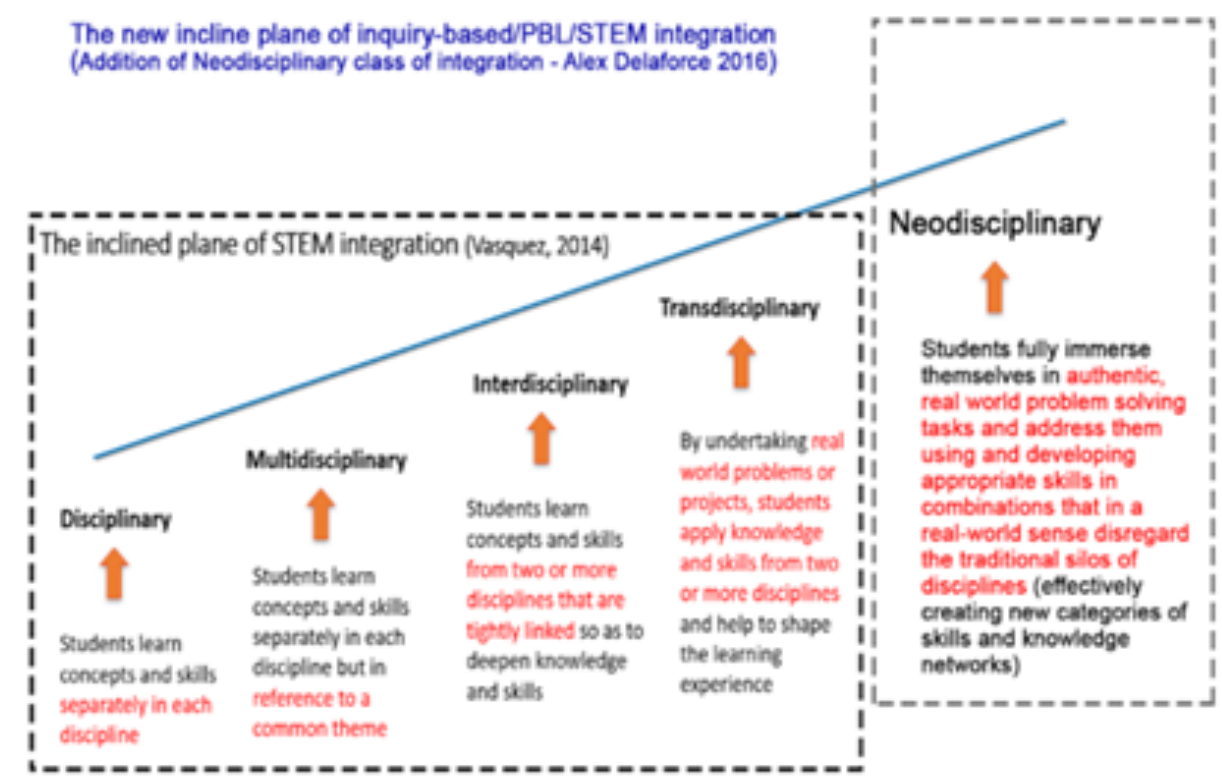

Source: Delaforce 2016 htto://delaforce info/wo-centent/uploads/2016/10/Neodisciplinarv-1 ons

Figure 2. The inclined plane of STEM integration (Vasquez, 2014) extended (Delaforce, 2016).

Figure 3 illustrates an example of a transdisciplinary or neodisciplinary learning happening in STEM. The illustration of a block and tackle of four pulleys connects situated learning, engineering design, scientific inquiry, technological literacy, and mathematical thinking as an integrated system. Each pulley in the system connects common practices within the four STEM disciplines and are bound by the rope of community of practice. The pulley system must work in harmony to ensure the integrity of the entire system' (Kelly \& Knowles, 2016).

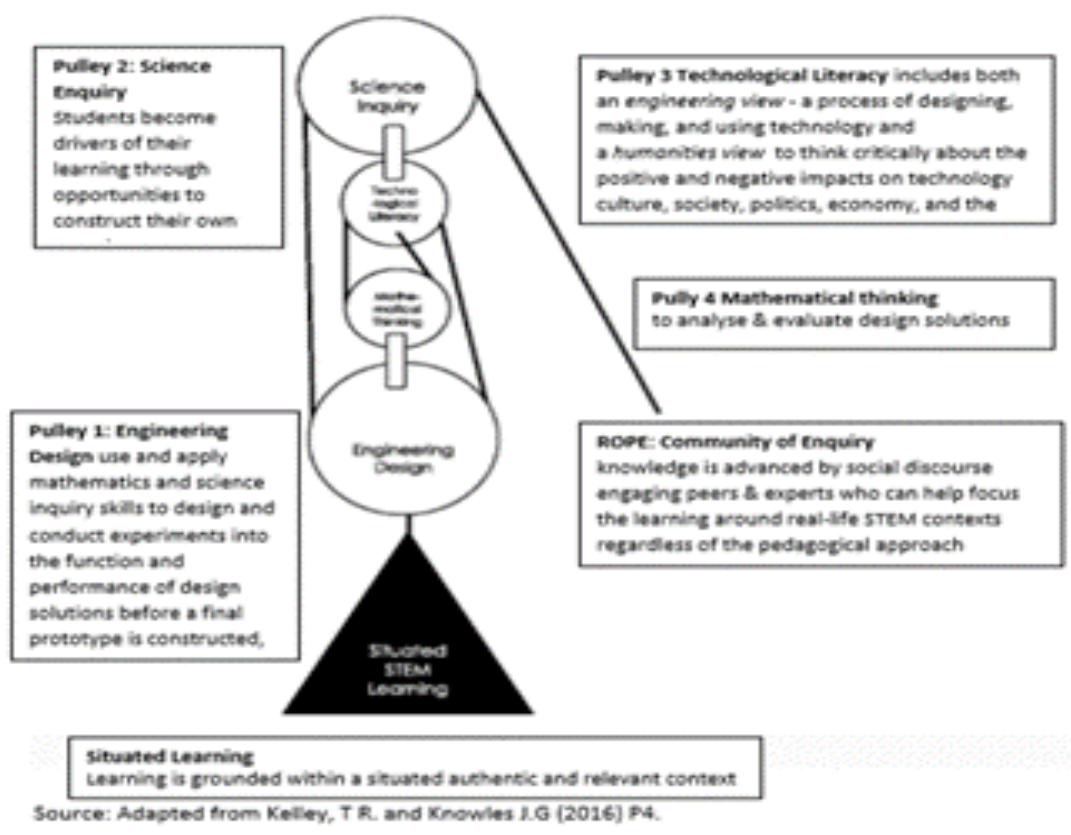

Figure 3. Graphic of conceptual framework for STEM learning. 
SEL happen as the students immerse in solving the problem through the activity designed by the teacher or through involvement in a real and authentic on the job training where schools work with the industry. In carrying out this group task, emotional intelligence is definitely challenged, group members have to put aside differences to collaborate, character building is happening. This kind of activity would give a real life experience to the students which is beneficial to him or her technically or emotionally.

The need to move away from discipline-based learning to multi-disciplinary/transdisciplinary approach is overwhelmingly clear. However to facilitate this, an overhaul of the curriculum is needed and this takes time. As an interim, an 'in-between' approaches between discipline-based learning and multi-disciplinary/transdisciplinary approaches can happen through problem based learning, project-based learning, inquiry based learning and design activity. The focus is on providing students a real world authentic problems, offering them opportunities to make connections across disciplines, develop their diagnostic, critical thinking and research skills to realise solutions to real problems. If handled well by skilled teachers these contextually situated, activity based approaches help students to make personal meaning of their learning experiences, increasing the probability that what is learned will be retained and can be transferred for later use. We owe the students to provide this opportunity to them. It is interesting to note that at the tertiary education level, many universities have already begun to teach interdisciplinary courses to engage students with a more realistic picture of society and industries' current needs, but this is not happening in school yet. A major challenge in progressing integrated approaches in schools is the readiness of teachers who have gone through specific disciplinary training in teaching colleges and universities. To produce teachers who are able to teach in an integrated manner, their training needs to focus on interdisciplinary themes and pedagogical approaches that encompass a broader spectrum of content, methodologies and practices. This cannot be achieved overnight. It requires a long-term perspective and planning. Another challenge is to teach the necessary knowledge within the amount of time allocated in school timetables. There is also a need to keep STEM knowledge relevant, so that it does not become outdated. Engaging external professionals or experts can make integrated teaching and learning more contextual, meaningful and impactful. For example, schools can employ scientists, engineers and digital specialists to: coach students; co-teach with teachers; involve students in their ongoing research and innovations; and guide them to design experiments and create their own innovations. This can bridge or overcome teachers' lack of readiness or apprehension about adopting an interdisciplinary approach while preserving the individual disciplines intact to serve the specific technical requirements of higher education, industry and specialisms within the field.

\section{Rethinking Subjects Offered in Schools}

Critique have been raised from the theorists and practitioners about the relevance of subjects offered in educational institutions today (Wyse et al., 2018). Existing subjects have been taught in schools from the first industrial revolution till now, content have gone through changes but the subject matter remains. Some subjects are already 2000 years old. Charles Fadel, founder of the Center for Curriculum Redesign and a visiting practitioner at Harvard's Graduate School of Educations suggested that in keeping pace with revolutions in society and technology we need to 'distil each existing discipline into its core essential questions and restructure the information to highlight these concepts and meta-concepts'. This suggestion is urgent and relevant as critique felt that learners' thinking does not reflect the ways in which traditional subjects structure its knowledge, thinking is more themefocused drawing across multiple disciplines and areas of knowledge especially in current context, cross-cutting issues are more important than the subjects offered (Wyse et al., 2018). With the advent of knowledge, the boundary between traditional subjects have also blurred and as new knowledge emerged, the labels of these subjects probably need to be rethink. A note to be taken is that redesigning does not mean to eliminate subjects all together overnight, but it is a thought that need to be pondered upon for long term planning.

Finland in its curriculum reform has created a specific time in its timetable called 'phenomena teaching' where interdisciplinary topics are being explored together with students as they dig into the chosen phenomena and where their focus is about life and not scores (Briggs, 2019; Stillman, 2019). Early data in Finland have shown that in the two years since it was implemented across Helsinki, students learning outcomes have improved (Briggs 2019). A number of schools in Ireland under Educate Together's patronage have also decided to temporary ditch traditional subjects and take 'phenomenon-based learning (PhBL)' and in their word 'to equip children with skills necessary to flourish in the world we live in'. PhBL adopts the humanistic approach by placing learners at the center, through this program students choose topics based on subjects and learnt about research methods. (The Irish Time, 2019).

\section{Conclusion}

There is a need for us to go back to basics, going back to the original goal of education which is to build character among our young people for the sustainability of life and human civilisation. It is not enough to impart only job related knowledge and skills, there is a need to assist our young people of today to understand and accept oneself and respect others before we can rope them 
into nation building, global citizenship building. In another word, we need to humanise education. In carrying out this task, curriculum developers need to explore the relatively uncharted terrains of humanistic curriculum, ponder over the suitability of existing subjects offered in schools today and look at a more integrative approach which is more relevant to current living. It is not an easy task, but nevertheless, a very important task in order for character building and fulfilling the emerging needs of this century.

\section{References}

Al-Attas, S. M. N. (1997). The Concept of Education in Islam: A framework for an Islamic philosophy of Education. Library of Islam Ltd.

Briggs, S. (2019). Traditional subjects: can we do without them? Retrieved 12 July 2019 from www.opencolleges.edu

Chowning, J. T., \& Fraser P. (2007). An Ethics Primer. Seattle, WA: Northwest Association for Biomedical Research.

Collaborative for Academic, Social, and Emotional Learning (CASEL). (2015). Effective Social and Emotional Learning Programs. Chicago: CASEL.

Costa A.L., \& Kallick, B. (Eds.) (2000). Activating and engaging habits of mind. Virginia: Association for Supervision and Curriculum Development.

Costa, A.L. (1991). The school as a home for the mind. Illinois: Skylight Training \& Publishing.

Delaforce. (2016). The new incline plane of inquiry-based/PBL/STEM integration. Retrieved from http://delaforce.info/wpcontent/uploads/2016/10/Neodisciplinary-1.png

Devereux Student Strengths Assessment (DESSA). (2018). The DESSA SEL Inventory: Strength-based approach to promoting positive student bahavior.

Dewey, J. (1956). The Child and the Curriculum and The School \& Society. Chicago: The University of Chicago Press.

Dewey, J. (1916). Democracy and Education. New York: Macmillan World Economic.

Dworkin, M.S. (1959). Dewey on Education. New York: Teacher College, Columbia University.

Educating the whole child TOKKATSU. Retrieved 01 July 2019 from www.p.u-tokyo.ac.jp

Fauzan Akmal, F., \& Mariyat, A. (2017). Humanistic Approach. In Education According to Paulo Freire. At-Ta'dib. 12(2), December 2017. Retrieved July 01, 2019 from https://ejournal.unida.gontor.ac.id

Freire, P. (1970). Pedagogy of the oppressed, translated by Myra Ramos into English.

geniusinchildren.org Retrieved 01 July 2019

Harvey, L. (2000). New Realities: The relationship between higher education and employment. Tertiary Education and Management, 6, 3-17. Netherlands: Kluwer Academic Publishers

Ikeda, D. (2010). Soka Education: For the Happiness of the individual (2 $2^{\text {nd }}$ ed.). Middleway Press.

Kelley, T. R., \& Knowles, J. G. (2016). A conceptual framework for integrated STEM education. International Journal of STEM Education, 3(1). https://doi.org/10.1186/s40594 016-0046-z

Longstreet, W.S. \& Shane, H.G. (1993). Curriculum for a new millennium. Boston: Allyn and Bacon.

Macneil, A. J., Prater D. L., \& Busch, S. (2009). The effects of school culture ad climate on students' achievement. International Journal of Leadership in Education. 12(1), 73-84. 
Marope, M. (2017). Future Competences for Future Generations. S. Popa (ed.), IBE IN FOCUS. Geneva, IBE-UNESCO, 81-89.

Ng, S. B. (2010). Creating Thoughtful Classroom, Implementation of thoughtful science curriculum by master teachers. Germany: Lambert Academic Publishing.

OECD. (2018). Social and Emotional Skills Well-being, Connectedness and Success. OECD.

Paige, J. (2009). The 21st century skills movement. Educational Leadership, 9(67), 11-11.

Perkins, D. (1992). Smart schools - From training memories to educating minds. New York: The Free Press.

The Irish Time (19 March 2019). Could traditional subjects become a thing of the past in Irish schools. Retrieved from https:/www.irishtimes.com/news/education/could-traditional-subjects-become-a-thing-of-the-past-in-irish-schools1.3821632

Saylor J. G., \& Alexander W. M. (1974). Planning curriculum for schools. New York: Holt, Rinehart and Winston.

Stillman, J. (2019). Why the best schools in the world is rethinking subjects. Retrieved from www.inc.com

Toffler, A. (1974). Learning for Tomorrow. Random House Inc.

Udall A. J., \& Daniels, J. E. (1991). Creating the thoughtful classroom. Arizona: Zephyr Press.

Wiggins, G. (1987). Creating a thought-provoking curriculum. American Educator, Winter, 10-17

World Economic Forum (2016). Global Challenge Insight Report. The Future of Jobs. Geneva, Switzerland.

Wyse, D., Hayward, L., Higgins, S., \& Livingston, K. (2018). Traditional School Subjects versus progressive pedagogy. The Curriculum Journal, 29(3), 295-297. https://doi.org/10.1080/09585176.2018.1487668

Vasquez, J. A. 2015. STEM - beyond the acronym. Educational Leadership, 72(4), 1015. Retrieved from https://d41 super.files.wordpress.com/2014/12/stem-beyond-the-acronym.pdf 